\title{
A emergência do transtorno de personalidade borderline: uma visão comportamental
}

\author{
Ana Carolina Aquino de Sousa \\ Consultório particular, Goiânia \\ Luc Vandenberghe \\ Consultório particular, Goiânia \\ Pontifícia Universidade Católica de Goiás
}

\begin{abstract}
RESUMO
No fim do século passado, o transtorno de personalidade borderline se estabeleceu como uma categoria importante na psicopatologia. Emergiu dentro da abordagem psicanalítica, num contexto histórico específico que o possibilitou e conquistou em poucas décadas um lugar importante na psiquiátrica oficial. De um conceito opaco e questionado nas margens da nosologia, transformou-se num diagnóstico que, sustentado pela autoridade do DSM, se aplica a uma percentagem importante da população psiquiátrica. Além disso, um tratamento comportamental foi empiricamente validado como terapia de preferência para este transtorno. Uma vez que o significado de um termo é função da história da comunidade em que emergiu, torna-se primordial reportar ao comportamento dos cientistas da época e de suas práticas para a produção do conhecimento. Nesta revisão da literatura, consideramos o conceito de borderline como produto de contextos sociais complexos que geraram mudanças na teoria clínica. Examinamos as origens destas mudanças em dois sentidos. O primeiro é a emergência do conceito diagnóstico borderline na literatura, tanto dentro da psicanálise como dentro da psiquiatria. O segundo é a possibilidade de entender a referida patologia, como resultado dos contextos interpessoais e familiares da modernidade. Sugere-se que é esta análise que tornou o conceito acessível à terapia comportamental.
\end{abstract}

Palavras-chave: transtorno de personalidade borderline; análise histórica; psicopatologia.

\section{ABSTRACT \\ The emergence of borderline personality disorder: a behavioral view}

At the end of the past century, borderline personality disorder was established as an important category in psychopathology. A specific historical context made its emergence possible within psychoanalysis. In a few decades, it transformed from an opaque and questionable concept at the fringes of psychodynamic theory, into a respectable diagnosis that, sustained by DSM authority, is applied to an important percentage of the psychiatric population. A behavioral therapy was empirically validated as the treatment of choice for this disorder. Considering that the meaning of a term is determined by the history of the verbal community that uses it, we went back to the practices of knowledge production of the scientists of the epoch. This made it possible to understand the borderline concept as a product of social contexts that engendered changes in clinical theory. We examine these changes in two senses. First, we look at the emergence of the diagnostic concept in the respective literatures of psychoanalysis and of psychiatry. Second, we try to understand the salience of the borderline personality pattern as the result of the interpersonal contexts of the modern age. We suggest that this analysis is necessary to make sense of the concept within the behavioral view.

Keywords: borderline personality disorder; historical analysis; psychopathology.

O presente trabalho pretende explorar duas dimensões da emergência de um transtorno psiquiátrico. Num primeiro momento procura-se entender como surgiu o conceito do Transtorno de Personalidade
Borderline como noção psicopatológica. Num segundo momento, buscam-se dicas na literatura acerca os fatores etiológicos desta patologia moderna. 
O conhecimento da história consiste em identificar quais as variáveis que controlam o comportamento de um indivíduo, em particular, ou de uma comunidade, em geral. Assim, conduzimos um levantamento a respeito da história dos comportamentos dos cientistas da época e de suas práticas para a produção do conhecimento, partindo do princípio de que o comportamento de um indivíduo (também de um cientista ou um clínico), bem como de um grupo (uma classe profissional, uma subcultura científica) é função de sua história. Procuramos identificar práticas relevantes da comunidade verbal em que o termo diagnóstico surgiu, e algumas contingências socioverbais que podem nos ajudar a entender o surgimento deste novo conceito.

\section{O Surgimento do Termo 'Borderline'}

Em 1905, Kraepelin já escreve que existiam diversos estados 'limítrofes', entre insanidade e condições normais ou apenas estranhas. Ao mesmo tempo, a psicanálise estava desenvolvendo um conjunto de conceitos e uma prática científica que, mais tarde, iriam possibilitar falar sobre uma personalidade borderline. No início, porém, a maioria das pesquisas dentro da abordagem psicanalítica envolvia distúrbios, que eram considerados neuróticos, em pessoas relativamente bem adaptadas socialmente (Mack, 1975). Havia métodos diferentes para o tratamento de pacientes classificados como neuróticos ou psicóticos. Esta classificação estava bem definida a partir da teoria freudiana, que havia desenvolvido um modelo explicativo da formação da personalidade. Englobava as defesas do ego, esclarecendo diferenças fundamentais entre a psicogênese, a estrutura de personalidade e os mecanismos de defesa de neuróticos e psicóticos (Mack, 1975; Millon, 1981).

Gradualmente começou a ficar evidente um grupo de pessoas que não se conformavam a esta dicotomia. Eram indivíduos que apresentavam sintomas neuróticos, mas que numa análise apurada, não se encaixavam neste diagnóstico. Adolf Stern foi, de acordo com vários autores (Mack, 1975; Pfeiffer, 1974; Millon, 1981), o primeiro que descreveu formalmente este grupo residual sob o nome borderline. A partir da década de 40, apareceram mais esboços conceituais. Deutsch denomina de 'as-if' personalidade, aqueles indivíduos que se comportam como se eles mantivessem uma relação genuína e completa com a realidade. É como se respondessem adequadamente às circunstâncias da vida, mas transmitiam uma pseudoafetividade, em que, apesar de aparentemente tudo estar bem, internamente há uma vivência de vazio (Pfeiffer, 1974).
Nos anos 50, Wolberg e Frosh (Millon, 1981) e principalmente Knight (Mack, 1975; Pfeiffer, 1974; Chessick, 1974; Millon, 1981) são citados como autores que contribuíram com a descrição da categoria limítrofe. Parecia que a psicopatologia precisava ser revista. Havia uma dicotomização das patologias em termos neuróticos ou psicóticos de um lado, e a existência de pessoas que manifestavam uma combinação de características tanto neuróticas quanto psicóticas, de outro lado. Descrevendo este grupo com os termos existentes na época, como estando na fronteira entre o neurótico e o psicótico surgiu a utilização do termo 'borderline'.

Procuramos entender a produção científica dos investigadores acerca dos pacientes, no seu contexto histórico. Sua teorização a respeito de pacientes que não se conformavam à teoria existente tinha como público, seus colegas psiquiatras e psicanalistas. Esta comunidade verbal pôde moldar novas formulações, à medida que conseguiam falar de modo coerente com as convenções da mesma comunidade, sobre o que estava acontecendo nos consultórios.

Partiu-se para a formulação de relações objetais proposta por Klein que permitia melhor falar sobre a instabilidade apresentada pelo borderline, já que a teoria freudiana ortodoxa dificultava a descrição das contradições extremas apresentadas pelo grupo de pessoas que não eram nem psicóticas, nem neuróticas. A teoria kleiniana com seus conceitos de cisão, objetos bons e maus, e identificação projetiva, possibilita falar sobre a instabilidade e o quadro clínico caótico apresentado pelo 'borderline'.

Segundo Fairbairn (1952, citado em Guntrip, 1974), por exemplo, o paciente teria perigosos impulsos. Seu ego é infantil e dependente. Isto se dá, de acordo com o autor, devido a uma falha na relação objetal materna. A mãe não o amava por ele mesmo. A não ser que as relações objetais fossem boas suficientemente para manter a criança em contato genuíno como o mundo externo, poderia vir a ser progressivamente mais dominada pelo medo, e perder o contato com a realidade externa, voltando-se para o mundo da fantasia.

Tais formulações foram integradas por Otto Kernberg (1967), em sua organização de personalidade borderline. Ele propôs uma nova teoria das relações objetais que enfatizava a importância das relações com pessoas significativas em geral. Desde o nascimento, as relações com estas pessoas, sob o impacto de afetos fortes seriam internalizadas como memória afetiva. As pessoas absorveriam o que ocorre ao seu redor. $\mathrm{O}$ ego armazenaria informações, integrando-as e aprendendo a selecionar o que é importante, bom, 
ruim, útil e perigoso. Assim, tornaria possível o controle do próprio corpo e, gradativamente, um mundo interno vai sendo construído. A possibilidade de falhas nestes processos podia explicar de maneira mais elegante do que a teoria tradicional, o quadro clínico do paciente borderline (Kernberg, 2003a, 2003b). Esta teoria se tornaria o veículo mais importante da popularização do conceito de borderline.

"The Seeds of the Self" (Kernberg, 2003a) aponta um aspecto interessante do contexto histórico dos anos 60 , em que a psicanálise estava marginalizada, sendo, portanto, retirada dos cursos de psiquiatria. Uma forte crítica era que a psicanálise era lenta, com alto custo e que não estava sendo eficaz. Pode-se imaginar uma comunidade cujas perspectivas de emprego e seu status científico, estavam ameaçadas. A psicanálise estava sendo ameaçada. As contingências de sobrevivência desta "cultura" científica favoreceram mudanças nas práticas dos estudiosos e clínicos que constituem a psicanálise. Isso ocorreu a partir da proposta de Kernberg que, ao criar uma 'Nova Psicanálise', argumentava superar a rigidez e impotência da velha guarda.

De acordo com a visão de Skinner (1974), ao construir um 'saber' o cientista está sob controle (embora nem sempre tenha consciência disto) não só do objeto que está analisando, mas também de sua história em particular, que moldou uma ou outra forma de pensar, e ainda, deve-se considerar que está inserido numa sociedade, que reforça certas linguagens na descrição dos objetos que estuda.

Percebe-se que os 'novos' psicanalistas apresentaram um novo discurso para se restabelecer. Em termos da análise funcional, pode-se dizer que as contingências sócioverbais, empregatícias e econômicas da época modelaram o comportamento dos autores. O público (isto é, colegas e instituições) cujas reações são consequiências importantes (reforçadores e punições) do comportamento verbal do científico, constitui-se num conjunto de contingências poderosas. Isto não significa, contudo, que este publico utiliza conscientemente estas estratégias. A seleção por conseqüências apenas significa que as condições numa dada sociedade reforçam as práticas culturais mais eficazes. Assim as novas práticas verbais estão sob controle do objeto da teorização (no caso do termo borderline, isto é a realidade no consultório) e a evolução sociocultural.

\section{Comportamento Interpessoal}

Enquanto a teorização psicanalítica sobre as patologias da personalidade, continuou, pelo seu conteúdo inacessível ao terapeuta comportamental, o modelo
Interpessoal foi uma inovação teórica que trouxe alguns pré-requisitos conceituais para que o comportamentalista pudesse tratar dos transtornos de personalidade. Segundo Leary (1957), a variedade dos comportamentos interpessoais pode, baseada nas suas semelhanças, ser distribuída em classes de comportamento representadas como segmentos de um círculo. $\mathrm{O}$ autor propôs oito categorias para descrever todos os padrões interpessoais possíveis, sendo que um indivíduo sempre mostra mais comportamentos pertencendo a certos segmentos do que outros. Tal preferência para uma certa parte do círculo define a sua personalidade. A rigidez, inflexibilidade e o uso excessivo e intenso de estratégias pertencente a um segmento particular, podem ser caracterizados como transtorno de personalidade.

Um ponto central no trabalho de Leary (1957) é a idéia de que os comportamentos interpessoais são operações empregadas pelas pessoas com a finalidade de manter relativo conforto e segurança. Estas operações induzem respostas complementares nos outros. Durante o desenvolvimento da nossa personalidade, aprendemos a utilizar estratégias que são eficazes para obter dos outros os comportamentos que supram as nossas necessidades.

Posteriormente, Kiesler (1986) elaborando idéias de Leary, propôs 16 categorias para descrever os diferentes padrões interpessoais possíveis, mantendo também que a característica básica do comportamento interpessoal (categorias ou segmentos do círculo) mal adaptativo é a sua rigidez e inflexibilidade. Uma pessoa bem adaptada usa de várias estratégias interpessoais dadas diferentes situações. Assim, a teoria do círculo interpessoal passa a explicar a organização da personalidade em termos de aprendizagem, de interações interpessoais. São as reações dos outros que confirmam ou validam suas experiências, idéia esta, que mais tarde seria retomada por Millon.

\section{A Formação da Personalidade Segundo o Behaviorismo Radical}

A visão do behaviorismo radical mostra similaridades acentuadas com o modelo interpessoal. Ambos rejeitam a existência de um 'eu' interior que dirige a ação do outro. Reagem contra o pressuposto que a personalidade é um eu que é responsável pela ocorrência de comportamentos (Skinner, 1998). Em uma linguagem behaviorista radical, pode-se definir o eu como um conjunto de respostas funcionalmente unificado, sendo que o importante é explicar a unidade funcional desse conjunto, estabelecendo as relações 
existentes entre estas respostas e suas variáveis de controle (estímulos discriminativos e conseqüências).

Personalidade consiste no repertório comportamental de cada um, e é multideterminado. Skinner (1998) apontava a importância de entender os três níveis de seleção do comportamento: filogênese, ontogênese e a cultura. Esses três fatores se combinam e interagem durante toda a vida formando o que chamamos de personalidade. Ao nascer, apresentamos comportamentos inatos (reflexos). Mas desde o momento inicial as contingências começam a influenciar a probabilidade futura dos nossos comportamentos. Podemos observar isso já nas primeiras interações de uma mãe com o seu bebê. Se a mãe espera a criança chorar para dar-lhe alimento, esta aprenderá que através do choro ganha comida. Entretanto, se a mãe a amamenta antes que chore, imaginando que pode estar com fome, o que a criança aprenderá será muito diferente - o alimento será, neste caso, contingente aos comportamentos que para a mãe são dicas de que o bebê está com fome.

Falar em personalidade significa apontar uma tendência a se comportar de uma dada maneira em função de uma história passada de reforçamento, que é individual. Refere-se, portanto, a um conjunto de comportamentos que ocorrem de forma consistente em muitas situações. Estes padrões consistentes são resultantes de um ambiente com contingências consistentes ao longo do tempo. Os pais, por exemplo, não mudam radicalmente na maneira de lidar com os filhos no dia a dia. A cultura valoriza e promove padrões consistentes de comportamentos porque é útil para predizer como vão se comportar e facilita a manutenção do funcionamento da sociedade. Há, entretanto, aquelas pessoas que adquiram padrões que não são adequados do ponto de vista da cultura, e que por isso, podem ser consideradas como apresentando um transtorno de personalidade (Parker, Bolling, \& Kohlenberg, 1998).

\section{Millon e a Inovação da Noção de Psicopatologia}

Um dos contribuintes preeminentes para o desenvolvimento do conceito de TPB como apareceu pela primeira vez no DSM (Manual Diagnóstico e Estatístico de Transtornos Mentais) em 1980, foi Teodore Millon. Seu envolvimento como clínico e teórico com os transtornos de personalidade era de longa data e seu papel em tornar o conceito diagnóstico acessível para terapeutas comportamentais foi importante. Sob influência do modelo interpessoal de Leary e das abordagens de aprendizagem (incluindo a teoria de Skinner), Millon (1969), propôs uma abordagem atra- vés da aprendizagem biossocial. Acentuava que a personalidade era formada por fatores biológicos combinados e interagindo reciprocamente com as experiências, no decorrer da vida. Assim, se o bebê é alegre e adaptável, torna-se mais fácil cuidar dele, e então, a mãe teria uma atitude positiva. Já se a criança é ansiosa e nervosa, os cuidados dispensados consomem mais tempo, e a mãe pode reagir com desânimo e/ou hostilidade. Há investigações que demonstram este jogo recíproco de influências (Gewirtz \& Boyd, 1977).

Defendia que a criança inicialmente explora o ambiente, apresentando grande flexibilidade e mutabilidade dos padrões de comportamentos. Na sua interação com as pessoas, seus comportamentos vão sendo selecionados pelas consequiências que os mesmos provocam. Portanto, as experiências levam ao aprendizado de estratégias adaptativas que passam a caracterizar nossa maneira de nos relacionarmos com os outros - ou seja, nossa personalidade. Os comportamentos persistem em função de uma história de reforçamento intermitente, e por isso, são altamente resistentes à extinção (Millon, 1969).

A etiologia da psicopatologia é explicada seguindo o mesmo raciocínio. Tanto a normalidade quanto a patologia devem ser consideradas como pontos num continuum. Isso significa que não há como definir uma linha divisória clara entre o normal e o patológico, uma vez que o comportamento pode ser adequado em um dado momento, e não em outro, dada a circunstância (Millon, 1969; 1981).

A influência do trabalho apresentado por Millon é inegável para a psicopatologia, já que foi convidado posteriormente a escrever o esboço de critérios operacionais dos distúrbios de personalidade no DSM III, e principalmente, porque inovou a visão tradicional de "normalidade" e "patologia", reinterpretando-a em termos de processos de aprendizagem que poderiam gerar níveis diferentes (num continuum) de saúde ou desadaptação, abordando-a em termos de comportamentos privados e interpessoais, tornando, assim, o transtorno de personalidade acessível à terapia comportamental. Até então, o conceito era puramente psicanalítico.

Segundo Millon (1969; 1981), o funcionamento da personalidade pode ser analisado, a partir da combinação de dois elementos: os comportamentos interpessoais e os tipos de reforçadores procurados. Ele propôs uma taxonomia de transtornos de personalidade, baseada nestes princípios, com suas respectivas explicações etiológicas.

O ponto central para a compreensão do cliente borderline nesta visão é que embora utilize diversas 
estratégias extremas e incoerentes, cuja finalidade é a busca permanente para evitar rejeição, acaba perpetuando suas dificuldades e impedindo esforços por uma vida melhor, já que fracassa em alcançar suas metas, resultando assim, em relacionamentos marcados por hostilidade, ansiedade e conflitos, que conseqüentemente, conduzem a comportamentos ainda mais desesperados (Millon, 1981).

\section{A Classificação Topográfica}

Nos anos subseqüentes, esforços foram feitos para a criação de um manual descritivo, adotando uma linguagem clara, que facilitaria o diagnóstico, com a pretensão de ser ateórico. Distancia-se de uma visão contextualista, como a de Skinner, à medida que se preocupa com a descrição topográfica dos diversos transtornos. A última versão do Manual Diagnóstico e Estatístico de Transtornos Mentais foi o DSM-IV-TR (APA, 2002). A seguir, apresenta-se como o manual descreve o transtorno de personalidade borderline, para então, discutir brevemente se esta definição pode ser integrado a uma visão behaviorista radical.

$\mathrm{O}$ indivíduo com Transtorno de Personalidade Borderline (TPB) apresenta um padrão instável no que se refere a relacionamentos interpessoais, autoimagem e afetos, padrões constantes de impulsividade, que estão presentes em uma variedade de contextos, tendo início na idade adulta, preenchendo cinco ou mais dos critérios citados abaixo (Tabela 1).

Tabela 1. Critérios Diagnósticos do TPB, segundo o DSM-IV-TR (APA, 2002)

\begin{tabular}{l}
\hline Critérios Diagnósticos \\
\hline 1. \\
2. Esforços para evitar um abandono real ou imaginário - são pessoas intolerantes à solidão; \\
idealização e desvalorização; \\
3. Perturbação da identidade - instabilidade constante da auto-imagem ou do sentimento do "eu"; \\
4. Impulsividade em duas ou mais áreas, prejudicando significativamente a sua vida (sexo, abuso de substân- \\
cias, comer compulsivo etc); \\
5. Comportamentos, gestos ou ameaças de suicido ou de comportamentos automutilantes; \\
6. Instabilidade afetiva - oscilação freqüente de humor; \\
7. Sentimentos crônicos de vazio; \\
8. Raiva intensa ou dificuldade em controlar a raiva; \\
9. Episódio de ideação paranóides relacionados ao stress à sintomas dissociativos intensos.
\end{tabular}

Uma pergunta relevante é: será útil uma classificação como a apresentada no DSM-IV-TR (APA, 2002), dentro de uma proposta contextualista?

Devido aos princípios filosóficos do behaviorismo radical, pode-se apontar objeções ao uso de um manual classificatório. Dentre elas, o obscurecimento da individualidade, a possível estigmatização em função do rótulo recebido, e ainda, a não identificação de variáveis controladoras do comportamento, pois são estas que direcionam a intervenção. Uma análise topográfica pode distanciar a possibilidade de uma análise funcional, uma vez que ao deixar de identificar a função do comportamento corre-se o risco de punir uma melhora do cliente, por causa de suas características topográficas (Kohlenberg \& Tsai, 1987; 1994; 1995b; 2001; Koerner, Kohlenberg \& Parker, 1996; Cavalcante \& Tourinho, 1998).

Algumas vantagens práticas são apontadas, contudo, por Koerner e cols. (1996) para a utilização de um sistema de classificação diagnóstico. Pode alertar o terapeuta para ocorrências de problemas e melhoras dentro da sessão. Dar nomes para classes de respostas auxilia na identificação de comportamentos similares entre si. Ressalta-se que, sendo os transtornos de personalidade sinônimos de problemas difíceis de tratar, um processo diagnóstico que os identifique, leva o terapeuta a uma maior tolerância às lentas mudanças (ao invés de comportar-se impacientemente com a demora dos progressos) e aumenta a probabilidade de que reforce as pequenas melhoras, pois considera que a obtenção da saúde é um processo contínuo. Portanto, a conclusão de um diagnóstico é útil porque pode ter impacto sobre as mudanças no repertório do cliente. Pesquisas sobre transtornos de personalidade enfatizam a continuidade entre o saudável e o patológico, e assim, terapeutas influenciados por estes dados, podem ser menos susceptíveis a estigmatizar o indivíduo, ou seja, são mais sensíveis à natureza contextual do transtorno e ao reforçamento de melhoras. Contudo, do ponto de vista behaviorista radical, o sistema classificatório deve ser complementado com uma análise funcional. Por isso, será discutida e descrita a seguir uma visão analítico-comportamental a respeito da formação do eu "normal" e do eu borderline. 


\section{A Formação "normal" do eu segundo o Behaviorismo Radical}

Kohlenberg e Tsai (1987), propuseram a Psicoterapia Analítico-funcional (FAP), fundamentada no behaviorismo radical. Nos anos subseqüentes (1991/ 2001; 1995a) apresentaram sua formulação do desenvolvimento do "eu". Na teoria proposta, o "eu" emerge inicialmente como uma unidade funcional a partir de unidades maiores diretamente aprendidas, como "estou com calor, estou com fome, estou aqui" - tendo em comum, portanto, o "eu estou". Uma vez estabelecidas unidades funcionais como "eu estou", "eu quero", a criança passa a se expressar com uma série de combinações de palavras que nunca havia dito ou ouvido anteriormente. Posteriormente, emerge o eu como referência, primeiro sob controle de estímulos públicos, depois privados. Deste modo, a experiência do 'eu' é explicada através da identificação e descrição do que é vivenciado. É resultante de contingências externas - as pessoas com as quais um indivíduo convive modelam seu repertório, e que em um dado momento, deixa de ser sujeito ao controle dos outros. Este é o momento em que a pessoa passa a se ver como única e constante, mesmo que as circunstâncias às quais é exposta estejam em constante mudança, pode-se ouvir afirmações sobre o eu. Isto foi possibilitado a partir da comunidade verbal que reforça a palavra eu repetidas vezes diante de situações nas quais o indivíduo estava se comportando.

Uma vez que a aprendizagem do eu é complexa e imprecisa, ocorrem necessariamente, falhas neste processo. O indivíduo pode ser exposto a contingências em que o eu não é colocado sob controle de eventos privados, mas apenas de eventos públicos, o que pode levar à instabilidade e dependência (Conte \& Brandão, 2001). Portanto, pode-se dizer que em um desenvolvimento normal as afirmações acerca do eu são inicialmente controladas por eventos públicos e que posteriormente, ficam sob controle de eventos privados.

\section{Fatores Etiológicos do Transtorno de Personalidade Borderline}

\subsection{Elementos biológicos}

Embora os autores geralmente relacionam o desenvolvimento do TPB com fatores na história de vida do indivíduo, há pesquisa sobre a predisposição biológica. Não se pensa mais em termos dicotômicos de hereditariedade ou aprendizagem, mas de um jogo complexo de interação entre ambos. A teoria de seleção por consequiências de Skinner $(1966 ; 1981)$ é um modelo estocástico onde há variação e seleção nos níveis genético, ontológico e cultural. A teoria de Millon (1969), que possibilitou pela primeira vez uma abordagem comportamental do TPB, sugere que é a criança que determina em grande parte como seu ambiente social o tratará. Os comportamentos de cada bebê já têm características pessoais que, como exposto anteriormente, influenciam as interações com sua mãe e outros adultos.

Apesar de não existir nenhum marcador genético ou biológico, como um teste sangüíneo ou um gene, algumas pesquisas têm demonstrado resultados interessantes (Kreisman \& Straus, 1989; Siever \& Davis, 1991; Paris, 2000; Fonagy, Target \& Gergely, 2000; Livesley, 2000). Abaixo, seguem-se alguns achados relevantes.

Há uma correlação entre comportamentos impulsivos e anormalidades no metabolismo de serotonina. Esta relação é apoiada pelo fato de que certas medicações têm aliviado os sintomas no TPB. Contudo, o que ocorre é uma melhora, sendo que muitos dos sintomas ainda persistem.

Comportamento autodestrutivo, como abuso de comida, álcool ou outras drogas, e automutilação, podem ser vistos como tentativas de obter efeitos calmantes. A automutilação, por exemplo, como qualquer outro trauma físico, resulta na liberação de endorfina, trazendo a sensação de relaxamento.

O TPB tem sido associado a certas desordens neurológicas, como: Distúrbios de Aprendizagem, Transtorno de Déficit de Atenção e Hiperatividade, Epilepsia, Traumatismo Craniano e Encefalites. Além disso, atividades anormais de ondas cerebrais no lobo temporal, sugerem possíveis disfunções, com produção também anormal de neurotransmissores durante os testes.

Finalmente, parece haver uma atividade distinta de ondas cerebrais, durante o sono, na maioria dos pacientes com diagnóstico de TPB, conhecida como latência REM: um curto período de tempo precedendo a chegada dos sonhos, uma característica bem documentada em pacientes deprimidos. Estes padrões foram encontrados na maioria dos borderlines, estando deprimidos ou não. Um ou ambos os pais de borderlines também apresentam estas características. Parece sensato admitir que pelo menos uma vulnerabilidade a frustrações, traumas e eventos estressores é herdada, que interage com fatores no ambiente no qual o indivíduo está inserido. Todavia, a inferência tem sido a de que os padrões borderlines sejam ensinados de pais para filhos, ao invés de transmitidos geneticamente. São necessários mais estudos que envolvam uma grande amostra de 
gêmeos idênticos. Além disso, avaliações sistemáticas dos pais ao longo da infância deveriam ser feitas.

\subsection{Ontogênese cultural}

O primeiro estudo sistemático de pacientes borderlines foi publicado por Grinker e cols. (1968). Os autores questionaram a que se devia a emergência da síndrome - características específicas da cultura, como o stress da vida urbana, o aumento da ansiedade existencial, bem como as várias mudanças tanto na estrutura familiar como na social. Deste modo, chamaram a atenção para o funcionamento do paciente em relação ao seu ambiente social e apontaram a possibilidade do surgimento de novos tipos de problemas psicológicos devido a novas condições sociais. Idéia esta, corroborada posteriormente por diversos estudos, conforme será apresentado nesta seção.

No que se refere à topografia do TPB, os clientes com este diagnóstico trazem ao terapeuta sentimento de impotência e confusão, pois afirmam não saber quem são, do que gostam ou o que esperam da vida. Seus comportamentos (tanto públicos quanto privados) tendem a ser contraditórios entre si e mudam rapidamente. É comum desistirem do tratamento ou não aproveitarem bem a terapia. Diante de situações de escolhas, tendem a ter dificuldades para tomar decisões. É freqüente a tentativa de suicídio em função da intensidade do sofrimento. Muitas vezes, relatam crises de identidade (Conte \& Brandão, 2001). Devese lembrar, entretanto, que para um diagnóstico comportamental, mais importante que a topografia, é analisar as funções destes comportamentos na vida de uma pessoa, em particular.

O cliente relata, geralmente, "eu me sinto vazio". Segundo Kohlenberg e Tsai (1991/2001; 1995a), tal declaração ocorre em função da falta de estímulos discriminativos privados que controlam o eu. Quando a experiência do eu depende de estímulos externos, a pessoa pode se sentir instável e insegura. Assim, a sensação descrita como vazio pode ser entendida a partir da ausência de estímulos externos, que antes estavam presentes. Além disso, a ausência destes estímulos externos pode levar à sensação de despersonalização. Com isso, a pessoa pode isolar-se, criando um contexto para ser ela mesma, livre do controle dos outros. Muitas podem passar a esquivar-se tanto fisicamente quanto emocionalmente dos outros, pois assim, não dão oportunidade para que estes as controlem. Temem perder a sua identidade ao se envolverem (Melges \& Swartz, 1989; Conte \& Brandão, 2001; Livesley, 2000).
Kohlenberg e Tsai (1991/2001) apontam que a pessoa torna-se capaz de identificar quaisquer mudanças nos comportamentos dos outros, e estas servem como estímulos discriminativos para que ela mude sua forma de pensar, sentir e ver em relação ao eu. Pessoas com o eu sob controle de estímulos públicos não sabem o que querem, o que podem fazer e o que sentem, a menos que outras lhes digam o que fazer e o que é permitido sentir (Parker \& cols., 1998).

Por apresentarem pouco controle privado sobre a experiência do eu, a pessoa pode achar intolerável ficar só. De acordo com Kohlenberg e Tsai (1991/ 2001), o fato de temerem a solidão se explica não só pela invalidação, mas também pela experiência de negligências, em que suas necessidades básicas não foram atendidas. Enfim, pais que ao não fornecer suporte emocional quando imprescindível à criança, ou que a deixavam só, tornaram a experiência do eu assustadora, acarretando assim, na idade adulta, em buscas incessantes pela companhia de outras pessoas.

A pessoa, muitas vezes, busca evitar o sentimento de vazio, através de encontros casuais. Porém, à medida que ocorre uma aproximação mais íntima, a pessoa fica com raiva, sente-se sufocada e afasta-se. Seus comportamentos podem variar. É comum que estas pessoas apresentarem raiva excessiva (ou "explosões") e repertórios de esquiva. Podem ir do extremo da idealização do outro até a desvalorização. É comum expressarem necessidade de atenção e de intimidade, mas após um pequeno período de tempo, rejeitar o que o outro ofereça, podendo até pôr fim a relacionamentos.

Se baseados em idéias esboçadas por Millon (1969; 1981), autores comportamentalistas como Wasson e Linehan (1993), Linehan (1993), Linehan, Cochran e Kehrer (2001), e Koerner e Linehan (2002), apontam que indivíduos com TPB apresentam uma vulnerabilidade biológica que os leva a ser extremamente sensíveis a estímulos emocionais. Em geral, vêm de famílias em que seu relato em relação à sua própria experiência quando criança foi invalidada, ridicularizada e ignorada. Foi dito-lhes que não estavam sentindo raiva, por exemplo, quando, de fato, estavam. Além disso, os pais deixaram a mensagem de que os pensamentos, sentimentos e emoções devem ser controlados, o que invalida a vivência de dificuldades e a falta de apoio. As respostas da criança que estavam sob controle privado não foram reforçadas positivamente, mas sim punidas, o que levou ao reforçamento negativo de auto-relatos inadequados, pois para evitar conseqüências aversivas, a criança passa a vivenciar o self a partir de estímulos externos, o que a 
torna extremamente sensível ao humor e aos desejos dos outros.

Gunderson, Kerr e Woods (1980) realizaram um estudo que apóia as explicações etiológicas para a formação do borderline. Investigaram se havia características específicas que pudessem ser identificadas em famílias borderlines. Para isso, foram comparadas famílias de borderlines com famílias de pacientes psiquiátricos diagnosticados como esquizofrênicos e neuróticos.

Dentre as características específicas das famílias de borderlines, pode-se ressaltar o investimento dos pais na relação conjugal, em detrimento da relação pais e criança, sendo esta, negligenciada pelos mesmos, pois o casal tende a se atacar, utilizando a criança, não lhe oferecendo, portanto, atenção, empatia, apoio e proteção necessários, nem os cuidados básicos. As relações interpessoais são marcadas pela hostilidade e dominação. A mãe tende a ser não afetuosa. A criança é deixada de lado pelos pais, já que se centram nos seus problemas conjugais. A relação entre pais e filhos tende a ser pobre e distante. Este achado sugere uma possível explicação para a percepção que o borderline apresenta sobre os seus pais como sendo um 'grupo unido e/ou indiferenciado' (Gunderson \& cols., 1980). Além disso, apóia as explicações de Linehan da importância da negligência para o desenvolvimento deste transtorno.

A negligência, muitas vezes, leva a hospitalizações da criança. Os pais, que não estão aptos a lidar com este problema, podem tornar-se amargos e nervosos. Deste modo, a criança pode aprender desde cedo, a ser responsável em cuidar de outras pessoas e da própria casa (Gunderson \& cols., 1980).

Uma análise de psicopatologia nas mães de borderlines demonstrou a presença de diversos transtornos como esquizofrenia, TPB, depressão, alcoolismo, além de outros comportamentos como autoritarismo, infidelidade, sarcasmo, brigas, abusos verbais ou físi$\cos$ e punição inadequada aos comportamentos da criança. É comum, entretanto, encontrar psicopatologias em ambos os pais. Assim, de modo geral, os resultados sugerem falta de envolvimento dos pais com suas crianças (Gunderson \& cols., 1980).

Os resultados de Gunderson e cols. (1980) são importantes porque foram replicados por outros estudos empíricos de Soloff e Millward (1983) e Livesley (2000) que destacam os mesmos fatores da história de desenvolvimento que contribuem para a formação do borderline. Paris (2000) e Fornagy e Target (2000), revisaram estudos mais recentes acerca da influência da aprendizagem na formação do borderline, que também confirmam os resultados supracitados.

\subsection{0 contexto sociocultural}

Kreisman e Straus (1989) e Armony (1998) analisaram como a cultura atual favorece o desenvolvimento do TPB. O avanço tecnológico requer cada vez mais o compromisso individual com estudo e trabalho solitários, sacrificando assim, a socialização. Além disso, o aumento da taxa de divórcio, da utilização de babás, da dificuldade em alcançar relacionamentos íntimos mais estáveis, da necessidade de mudanças geográficas devido às pressões econômicas, contribuem para uma sociedade instável, com solidão, sentimento de vazio, ansiedade, depressão e dificuldade em confiar.

O conforto fornecido outrora por familiares e papéis sociais consistentes fora perdido, piorando os relacionamentos interpessoais e o isolamento, já que não se conta com o apoio de um grupo estável e/ou presente (Kreisman \& Straus, 1989; Armony, 1998).

A sociedade de muitos modos é um mundo de contradições. Somos levados a acreditar e defender a paz, embora as ruas, os filmes, os esportes, a televisão etc sejam marcados por agressão e violência. Fala-se em solidariedade, mas na prática, o capitalismo ensina o individualismo. A liberdade de expressão é valorizada no discurso e punida na prática. Ensina-se um mito: a polaridade. As coisas são boas ou ruins, certas ou erradas, brancas ou pretas. Contudo, embora o mundo não seja tão exatamente assim, as pessoas são levadas a acreditar que é (Kreisman \& Straus, 1989; Armony, 1998).

Não é de se causar estranheza o fato de que o TPB seja mais freqüente em mulheres. No passado, elas tinham essencialmente um curso de vida: se casar, ter filhos, cuidar destes e do lar. Hoje, necessitam de conciliar todos estes papéis com seu trabalho fora de casa, ou às vezes, tomar decisões sobre o que priorizar, o que pode torná-las confusas e estressadas sobre quem são ou o que querem. Já os homens, tiveram que fazer poucos ajustes em suas vidas. Não precisam desempenhar tantos papéis e não sofrem tantas pressões sociais como as mulheres. Concomitantemente ao aumento da liberdade feminina, as responsabilidades também foram maximizadas (Kreisman \& Straus, 1989; Armony, 1998). Portanto, todos os fatores sociais ressaltados aqui devem ser considerados, uma vez que contribuem com as contingências familiares e interpessoais relacionadas com o desenvolvimento do TPB. 


\section{CONCLUSÃO}

O presente artigo foi um esforço em resgatar brevemente o contexto em que o termo borderline surgiu e se desenvolveu. Além disso, descreveu-se a formação do transtorno segundo os diferentes níveis de seleção de comportamento, buscando-se um entendimento mais abrangente do mesmo. Uma análise do TPB em termos dos contextos interpessoais e socioculturais o torna possível entende-lo em termos comportamentalistas. Tal redefinição do transtorno de personalidade em termos da interação entre o indivíduo e seu ambiente social, torna possível seu tratamento pela Terapia Comportamental.

\section{REFERÊNCIAS}

American Psychological Association (2002). Manual Diagnóstico e Estatístico de Transtornos Mentais ( $4^{\mathrm{a}}$ ed.). Porto Alegre: Artmed.

Armony, N. (1998). Borderline: uma outra normalidade. Rio de Janeiro: Revinter.

Brandão, M. Z. S. (2000). Os sentimentos na interação terapeutacliente como recurso para a análise clínica. Em R. R. Kerbauy (Org.), Sobre Comportamento e Cognição, vol. 5 (pp. 222228). Santo André: ESETec.

Cavalcante, S. N. \& Tourinho, E. Z. (1998). Classificação e diagnóstico na clínica: possibilidades de um modelo analíticocomportamental. Psicologia: Teoria e Pesquisa, 14, 139-147.

Chessick, R. (1974). The borderline patient. Em S. Ariety (Org.), American handbook of psychopathology (pp. 808-819). New York: Basic Books.

Conte, F. C. S \& Brandão, M. Z. S. (2001). Psicoterapia Funcional-Analítica: o potencial de análise da relação terapêutica no tratamento de transtornos de ansiedade e de personalidade. Em B. Range (Org.), Psicoterapias cognitivo-comportamentais: um diálogo com a psiquiatria (pp. 19-33). Porto Alegre: Artmed.

Fornagy, P., Target, M. \& Gergely, G. (2000). Attachment and boderline personality disorder: a theory and some evidence. The Psychiatric Clinics of North America, 23, 103-122.

Gewirtz, J. L. \& Boyd, E. F. (1977). Experiments on motherinfant interaction underlying mutual attachment acquisition: The infant conditions the mother. Em T. Alloway, P. Pliner \& L. Krames (Orgs.), Attachment behavior. New York: Plenum.

Gunderson, J.G., Kerr, J. \& Woods, D. (1980). Families of borderlines. Archives of General Psychiatry, 17, 27-33.

Guntrip, H. (1974). Object Relations Theory: the Fairbairn Guntrip approach. Em S. Ariety (Org.). American handbook of psychiatry (pp. 828-842). New York: Grune \& Stratton.

Kernberg, O. (1967). Borderline personality organization. Journal of the American Psychoanalytic Association, 15, 641-685.

Kernberg, O. (2003a). The seeds of the self: an interview by Susan Bridle. Obtido em 11 de janeiro de 2003 do World Wide Web: http://www.wie.org/jl/kern.asp.
Kernberg, O. (2003b). The interview: by Chamda Rankin. Obtido em 11 de janeiro de 2003 do World Wide Web: http://www. psychotherapistresources.com/current/totm/kernberg.shtml.

Kiesler, D. J. (1986). Interpersonal methods of diagnosis and treatment. Em: J. O. Cavenara (Org.). Psychiatry ( $2^{\mathrm{a}}$ ed.) Vol. 4. (pp. 1-23). New York: Lippincotet

Koerner, K., Kohlenberg, R. J \& Parker, C.R., (1996). Diagnosis of personality disorder: a radical behavioral alternative. Journal of Consulting and Clinical Psychology, 64, 1-8.

Koerner, K. \& Linehan, M. M. (2002). Dialectical behavior therapy for borderline personality disorder. Em S. G. Hofman (Org.), Severe mental disorders: a handbook of empirically supported interventions (pp. 317-342). New York: Guilford Press.

Kohlenberg, R. J. \& Tsai, M. (1987). Functional Analytic Psychotherapy. Em: N.S. Jacobson (Org.), Psychoterapists in clinical practice: cognitive and behavioral perspectives. New York: Guilford Press.

Kohlenberg, R. J. \& Tsai, M. (1994). Functional Analytic Psychotherapy: a radical behavioral approach to treatment and integration. Journal of Psychotherapy Integration, 4, 175-201.

Kohlenberg, R. J. \& Tsai, M. (1995a). I speak, therefore I am: a behavioral approach to understanding problems of the self. The Behavior Therapist, 18, 113-116.

Kohlenberg, R. J. \& Tsai, M. (1995b). Functional Analytic Psychotherapy: a behavioral approach to intensive treatment. Em: W. O' Donohue \& L. Krasner (Orgs.), Theories of behavior therapy. (pp. 637-657). Washington: American Psychological Association.

Kohlenberg, R. J. \& Tsai, M. (2001). Psicoterapia analítica funcional: criando relações terapêuticas intensas e curativas. [trabalho original publicado em 1991; Tradução organizada por R. R. Kerbauy.] Santo André: ESETec.

Kreisman, J. J., Straus, H. (1989). I hate you - don't leave me: Understanding the Borderline Personality. New York: Avon Books.

Leary, T. (1957). Interpersonal diagnosis of personality: a functional theory and methodology for personality evolution. New York: Ronald Press.

Linehan, M. M. (1993). Skills training manual for treating Borderline Personality Disorder. New York: Guilford Press.

Linehan, M. M., Cocharan, B. N., Keher, C. A. (2001). Dialectical Behavior Therapy for Borderline Personality Disorder. Em: D. Barlow (Org.). Clinical handbook of psychological disorders. ( $3^{\mathrm{a}}$ ed.). New York: Guilford Press.

Livesley, W. J. (2000). A practical approach to the treatment of patients with Borderline Personality Disorder. The Psychiatric Clinics of North America, 23, 211-232.

Mack, J. (1975). Borderline States. Em J. Mack (Org.), Borderline States in Psychiatry. (pp. 1-27). New York: Grune e Stratton.

Melges, F. T. \& Swartz, M. S. (1989). Oscillations of attachment in Borderline Personality Disorder. America Journal of Psychiatry, 146, 115-120.

Millon, T. (1969). Modern Psychopathology. Philadelphia: Saunders.

Millon, T. (1979). Uma abordagem através da aprendizagem biosocial. Em T. Millon (Org.). Teorias da psicopatologia e per- 
sonalidade (pp. 332-336). Rio de Janeiro: Intramericana. [Texto original publicado em 1969].

Millon, T. (1981). Disorders of Personality DSM - III: Axis II. New York: John Wiley \& Sons.

Paris, J. (2000). Childhood precursors of Borderline Personality Disorder. The Psychiatric Clinics of North America, 23, 77-88.

Parker, C. R., Bolling, M. Y. \& Kohlenberg, R. J. (1998). Operant Theory of Personality. D. F. Barone, M. Hersen \& V. B. Van Hasselt (Orgs.), Advanced Personality. (pp. 155-171). New York: Plenum Press.

Pfeiffer, E. (1974). Borderline States. Diseases of the Nervous System, 35, 212-219.

Segal, H. (1979). Klein. Glasgow: Fontana.

Shea, M. T., Benjamin, L. S., Clarkin, J. F. \& Magnavita, J. (1999). Personality disorders: a discussion of current status and future directions for research, practice and policy. In session: psychotherapy in practice, 55, 1371-1384.

Siever, L. J. \& Davis, K. L. (1991). A psychological perspective on personality disorders. American Journal of Psychiatry, 148, 1647-1658.
Skinner, B. F. (1998). Ciência e comportamento humano. São Paulo: Martins Fontes. [Texto publicado originalmente em 1953].

Skinner, B. F. (1966). The philogeny and ontogeny of behavior. Science, 153, 1205-1213.

Skinner, B. F. (1974). About behaviorism. Nova York: Knopf.

Skinner, B. F. (1981). Selection by consequences. Science, 213, 501-504.

Soloff, P. \& Millward, J. (1983). Developmental histories of borderline patients. Comprehensive Psychiatry, 24, 574-588.

Wasson, E. J. \& Linehan, M. M. (1993). Personality disorders. Em: A. S. Bellack \& M. Hersen (Orgs.). Handbook of behavior therapy in the psychiatric setting. (pp. 329-353). New York: Plenum Press.

\section{Sobre os autores:}

Recebido: $14 / 06 / 2005$

Revisado: $13 / 11 / 2005$

Aceito: 13/12/2005

Ana Carolina Aquino de Sousa: Mestra em Psicologia. Pesquisa realizada com o apoio do CNPq. Endereço para correspondência: Rua 104, n. 966, Setor Sul - CEP: 74080-240 - Goiânia-GO (aquino_psy@ yahoo.com.br)

Luc Vandenberghe: Doutor em Psicologia (luc.vandenberghe@terra.com.br) 